\title{
Sustainable architecture: An appeal of the global environment
}

\author{
Ali Golrokhi ${ }^{1, *}$, Fatemeh Kateb ${ }^{2}$ \\ ${ }^{1}$ Department of Architecture, Semnan Science and Research branch, Islamic Azad University, \\ Semnan, Iran \\ ${ }^{2}$ Department of Architecture, Alzahra University, Tehran, Iran \\ *E-mail address: Ali.golrokhy@gmail.com
}

\begin{abstract}
Given the fact that protecting the environment and saving the exhaustible fossil resources is of high importance there is a need to utilize the clean and renewable energies like the solar energy more than ever before. The residential tower with a sustainable approach is not a common residential space and it has been adapted with the sustainable architecture where this in itself has engendered in the saving of the national resources. A sustainable designing means a dynamic balance among different systems of the environment and scientifically speaking it is a simultaneous attaining the sustainability of socio-economic, cultural and environmentalist systems.
\end{abstract}

Keywords: Sustainable architecture; Environment; Sustainable development; Energy

\section{INTRODUCTION}

A residential tower refers to a sustainable approach and sustainable architecture and its importance generally refers to the formation of consistent and accountable organizations for the sustainable architecture. The current administration of residential towers is in line with the conventional comfort and appropriate with the strategies within the sustainability of these spaces. Given the fact that protecting the environment and saving the exhaustible fossil resources is of high importance there is a need to utilize the clean and renewable energies like the solar energy so we can apply the natural ventilation to have cooling more than ever before. Applying the techniques and patterns to reduce energy consumption in the residential apartments, while reducing costs and reaching the environmental goals, are in line with informing the society. We have to take steps to reduce the fossil fuel consumption and to apply clean energies so that we can protect national resources and avoid environmental pollutions as much as possible. Designing sustainable residential towers is a kind of manipulation in the environment that strives to innovate solutions to reach a balance in line with the socio-economic goals so that these towers can provide a better quality of life for the current generation as well as the resources heritage in the future. In the contemporary architecture, in accordance with the climate -environmental criteria and the sustainability that gains importance day by day we need to think of new designs for the residential towers. Sustainability in architecture is not specific to the physique of the apartment; rather it refers to the protection of the environment and its energy resources (Sayyadi and Mahdavi, 2002). 
Due to the complexity of the issue of designing the residential towers for life and in accordance with the fact that building skyscrapers was made possible as elevators were innovated, special care must be directed at the feasibility issue so that residents' welfare is fulfilled and the desirability of a natural landscape with the aesthetics of the towers as the beautiful element of the city is understood. Man is created of desires and is not born of needs.

The basic condition in the environmental sustainability is to establish a dynamic balance among different systems in the environment and scientifically speaking it is a simultaneous attaining the sustainability of socio-economic, cultural and environmentalist systems. Establishing balance among the needs and desires of mankind is thought to be as elements of the global environmental system at present and in the future. Designing and construction of human spaces illustrate a responsibility compounded with ethics at a global level for the architecture. It is a move in correspondence with the environment followed by respect and humility. Sustainable architecture affects the texture - oriented issue and is formed as it links with land-orientation and, space and the environment. In fact apartment is part of the surrounding nature and is designed based ion socio-economic, cultural and specific climatology contexts. In the high buildings or modern skyscrapers, it is possible to use the solar energy, energy optimization, consistent air spaces, combination of internal spaces, building color, thermal mass of the materials, insulation, double skin facades along with thermal insulation. Man trying to compensate past weak points by applying the technology excessively so as to keep his needs whose results are a shortage of renewable energy sources in the future. It is imperative to have a reformist review towards modernism and an inbetween solution be found so that current needs are eliminated and those of the next generation be met. A sustainable approach in architecture has both turned to history and the IT and industry while here the issue that comes at the secondary stage is man and the environment (Gorjimahbani, 2010).

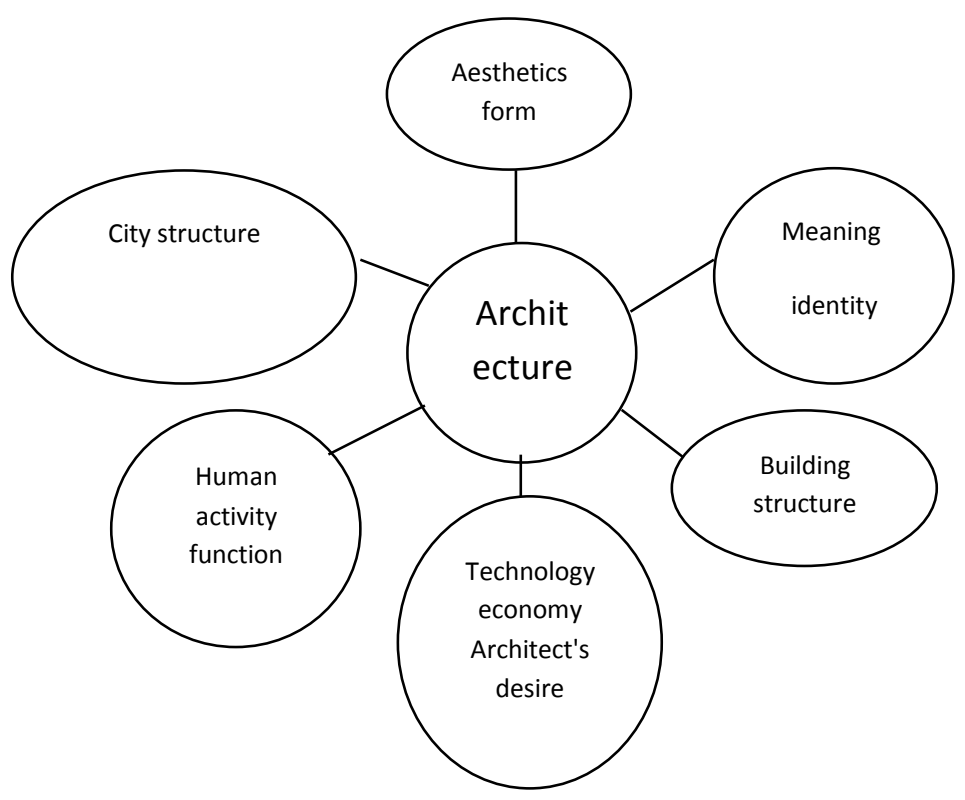

Figure 1. The sustainable architecture.

Although modernism has removed most problems of the classic architecture, the presence of mankind has long been forgotten within the dark and bright things of the space. The reliance of the twentieth century architecture on the disrupted things have resulted in 
architecture to have an inevitable role in disrupting the ecosystem and creating dangerous phenomena like the gap in the ozone layer, greenhouse gases and air pollution (Adams, 2001). Sustainable architecture as an element has striven to find a way for new horizons and or fulfilling a desirable life .It is obvious life, job, recreation and relaxation are designed by architects in the spaces where all of these have affected the global environment. Sustainable development has a qualitative concept that is concerned with progress and transcendence. Also, the need of the next generation is in the equality of making use of facilities within the intra and inter generation framework. Sustainable development is a positive variable in the environment that deals with opportunities and equal distribution while it attempts to protect the environment.

Today, one of the main designing issues of residential towers is to coordinate the architecture design with designing its installations and structure in accordance with the coordination of human activities, physical structure, energy and there environment which are the necessities of a sustainable designing. A residential tower can be successful when life goes on in it so that comfort is maximized and peoples' environmental and security concerns are met in line with a variety of innovation and aesthetics of the nature. However, the main goal of sustainable architecture and development is to meet the basic needs, to improve life expectancy, to preserve a better running of the ecosystem and a more secure future. It is noteworthy to say that in the architecture with the sustainable approach, experts in the transportation, land use, housing, urban development and economic expansion and the environment protection sectors must not work separately from each other. If there is coordination among the goals as well as the urbanization, architecture, and environmental activities, the desirability of the global environment and the life quality will be enhanced (Yorg, 1996).

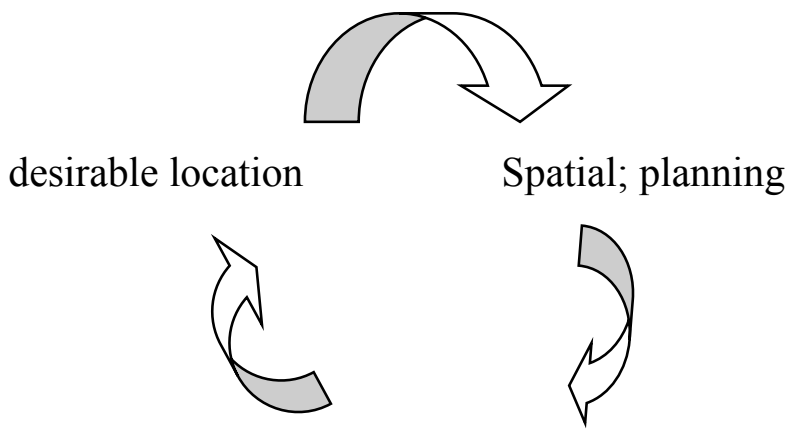

Figure 2. The chain generate sustainable utility.

\section{GOOD LOCATION}

Basic needs like food, housing, hygiene, and general health that had plagued the cites of the nineteenth century are already solved for the modern people and hence the feature of habitable becomes more and more important. Today, we cannot sacrifice quality for quantity and the visage of the city should be filled with a mass production along with living centers and identity. In line with the profound impacts of the life spaces and its effects on different groups of people as well as their desirability and quality during their lives and creation of a situation to enter the original depth of residential towers architecture should lead to a 
desirable life .Sustainable architecture strives to return to itself and to find its existence (Nasr, 2007).

\section{TERMS}

Tower: High buildings more than 10 stories. Residential environment: All the areas that fulfills all the necessary facilities for life and residence and includes compressed services Desirable house: It is a place where, in addition to appropriate spaces, the needs of the users are met, i.e. a place in proportionate with the life style and social customs and etiquettes. Sustainable development: A development through which the current social needs of man are met. It is a sort of expansion that is accountable to the needs of the next generation. Sustainable development is at the focus point as it refers to socio-economic categories and cultural issue of the cities.

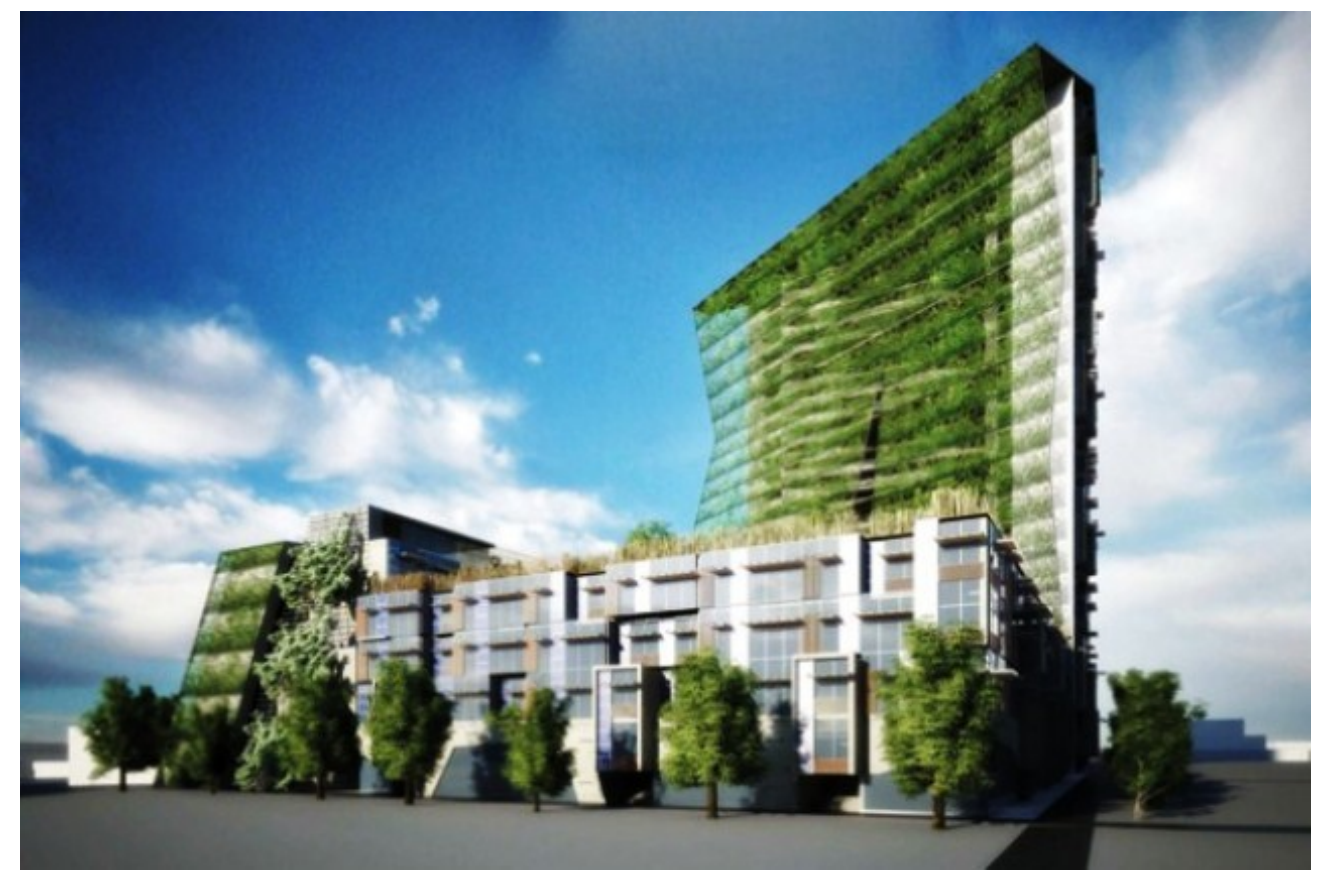

Figure 3. The area of green space in high-rise buildings the localization and sustainability in architecture today.

The concept of sustainable development is a main change in understanding the man's relations with one another but we can say that architectural mottos have lost importance in the sustainable development which is coordination between the natures of aesthetics and protecting the environment. Most importantly, the simplest steps to the most complex ones have been neglected. In the sustainable architecture, no situations including social and economic environmental situations are superior to the other and they in fact must be the same process while building. The issue of sustainability is an inevitable issue in architecture, a repeatable and valuable process. To Schultz, the sustainable architecture seeks to give sense to the environment through the nature. He, in the book "an introduction to architecture and space" states in his time of working the world had become e so much complex and 
transformational. Our environment has become polluted and utilization has become excessive (Schultz, 2003). Sustainable architecture has become a big motivation for the modern architecture and in the last years of the $20^{\text {th }}$ century the ecosystem architecture, an architecture that considers the forms and foundation and communication od life cycles as the starting point of the research and the end point of designing is concerned with the world of nature with all the necessities necessary for sustainability (Falamaki, 2002).

\section{CONCLUSION}

We can avoid the destructive role of building apartments, reduced open environment and reduced per capita income as rules and regulations change where all of this will aid life sustainability and global residence. In the sustainable architecture, the role of the environment and the energy and the social welfare will manifest which is closely related with the objectives of the sustainable development in such a way it follows socio-economic expansion.

\section{References}

[1] Sayyadi S., Mahdavi S. M., Quarterly of architecture and urbanization 20(68) (2002) 87-99.

[2] Gorjimahbani Y., Journal of architecture and urbanization in Iran 98 (2010) 91-100.

[3] Adams W. M. (2001). Green development, Environment and sustainability in the third world ( $2^{\text {nd }}$ edition), London Routledge.

[4] Yorg G. (1996). Aesthetics in architecture, Trans by Jahnshad Pakzad, Tehran: Shahid Beheshti University Press.

[5] Nasr S. H. (2007). Man of nature, trans by, Abdolrahim Govahi, Tehran: Bureau of Islamic Culture.

[6] Schultz C. N. (2003). Architecture, meaning and space, Trans, by Vida Norooz baarzjani, Tehran: Nashre jahan.

[7] Falamaki M. M. (2002). Roots and theoretical architecture inclinations, Tehran: Faza Press.

[8] Nguyen To Lan, Procedia - Social and Behavioral Sciences 85 (2013) 16-26.

[9] Mohadesehsadat Amiri Mohammadabadi, Shimaossadat Ghoreshi, Procedia Engineering 21 (2011) 580-590. 